\title{
Top Level User Specifications for Mask Inspection Microscope
}

\author{
A. Barty, J. S. Taylor
}

January 31, 2002

U.S. Department of Energy

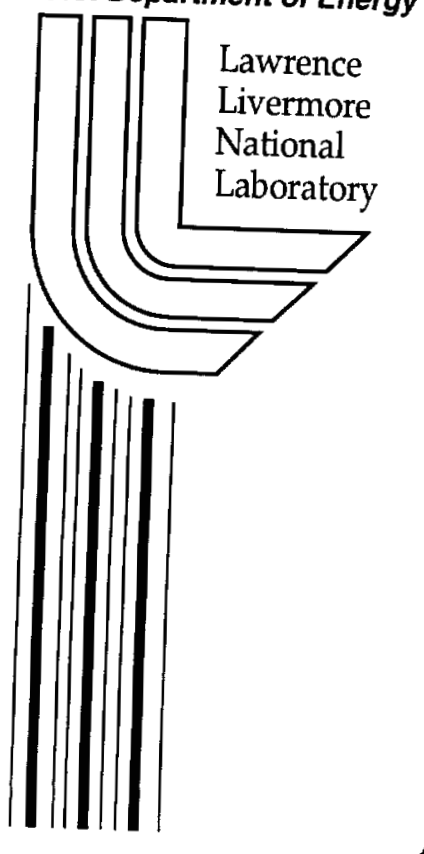




\section{DISCLAIMER}

This document was prepared as an account of work sponsored by an agency of the United States Government. Neither the United States Government nor the University of California nor any of their employees, makes any warranty, express or implied, or assumes any legal liability or responsibility for the accuracy, completeness, or usefulness of any information, apparatus, product, or process disclosed, or represents that its use would not infringe privately owned rights. Reference herein to any specific commercial product, process, or service by trade name, trademark, manufacturer, or otherwise, does not necessarily constitute or imply its endorsement, recommendation, or favoring by the United States Government or the University of California. The views and opinions of authors expressed herein do not necessarily state or reflect those of the United States Government or the University of California, and shall not be used for advertising or product endorsement purposes.

This work was performed under the auspices of the U. S. Department of Energy by the University of California, Lawrence Livermore National Laboratory under Contract No. W-7405-Eng-48.

This report has been reproduced directly from the best available copy.

Available electronically at http://www.doe.gov/bridge

Available for a processing fee to U.S. Department of Energy and its contractors in paper from

U.S. Department of Energy Office of Scientific and Technical Information P.O. Box 62

Oak Ridge, TN 37831-0062

Telephone: (865) 576-8401

Facsimile: (865) 576-5728

E-mail: reports@adonis.osti.gov

Available for the sale to the public from

U.S. Department of Commerce

National Technical Information Service

5285 Port Royal Road

Springfield, VA 22161

Telephone: (800) 553-6847

Facsimile: (703) 605-6900

E-mail: orders@ntis.fedworld.gov

Online ordering: http://www.ntis.gov/ordering.htm

OR

Lawrence Livermore National Laboratory

Technical Information Department's Digital Library

http://www.llnl.gov/tid/Library.html 


\title{
Top Level User Specifications
}

\author{
for
}

\section{Mask Inspection Microscope}

\author{
Milestone 1 for \\ AIM Design Study
}

\author{
Anton Barty and John S. Taylor \\ Lawrence Livermore National Laboratory \\ L-395, PO Box 808, Livermore, CA 94550 \\ (barty1@llnl.gov, jstaylor@llnl.gov)
}

January 31,2002

\author{
Submitted to: \\ Gil Shelden \\ International SEMATECH \\ 2706 Montopolis Drive \\ Austin, TX 78741
}

This work was performed under the auspices of the U.S. Department of Energy by University of California Lawrence Livermore National Laboratory under contract No. W-7405-Eng-48. The authors acknowledge funding from International SEMATECH under Project Lith 341. 


\section{User requirements}

This document compiles top-level user specifications for an EUV microscope for characterizing EUVL mask defects. Two broad categories of application are considered: 1) emulation of the imaging characteristics of a stepper for printability analysis (AIM mode); and 2) high-resolution imaging for obtaining a more detailed characterization of defects or mask features. It is generally assumed that the mask defects that are to be characterized have been located by a previous inspection procedure and the spatial coordinates of the defect can be transferred to the microscope.'

\section{Aerial Image Microscope (AIM) mode}

In this mode the microscope is designed to emulate the illumination and imaging characteristics of a stepper to enable rapid evaluation of mask defects without the need for a resist exposure step. In this mode the main uses of the microscope would be:

- Review of multilayer and pattern defects to determine their printability

- Defect review following a repair process to assess the success of the operation

- Investigation of the effects of illumination and NA on the printed image

- Process window analysis of defects and other mask features

\section{High-resolution mode}

This imaging mode is designed to obtain the highest possible resolution on the mask for the purposes of understanding and characterizing defects on both unpatterned (i.e. blanks) and patterned masks. Potential uses for this imaging mode include:

- Assessing the sensitivity of printability to numerical aperture

- Gaining sufficient information to associate defects with particular processes, such as multilayer deposition or patterning

- High-resolution data for repair of features that do not clearly appear in AIM mode (for example OPC features)

It would be advantageous to identify a system design for the microscope that could accommodate both AlM and highresolution imaging modes. This would enable the user to review a defect with effectively two lens objectives while not moving the mask or needing to reset the coordinate systems.

\section{Top-level specifications}

The heart of this document is a table of specifications for the proposed actinic mask inspection microscope. The AIM and high-resolution modes are considered separately, as both of these tools have nominally different optical systems. In many cases, the specifications for the two modes are identical, and suggest that a common platform might be adopted to address both intended uses. However, as this document does not constitute a design study, it would be premature to draw any conclusions with regard to the nature of the imaging system optics or magnification stages without that additional analysis.

We also distinguish between lithography nodes as appropriate, as we do not want to assume that the technology will remain the same for all nodes - there may be successive generations of EUV stepper and AIM-mode microscopes.

A commercial mask inspection microscope with an AIM mode capability is marketed by Carl Zeiss for optical lithography. Information on the specifications of the current commercially-available $193 \mathrm{~nm}$ mask inspection microscope from Zeiss is also included, where available from catalog information, for the purposes of comparison and critical review.

The table is split into sections according to the nature of the data as follows:

Fixed specifications: Technology-related specification values that are neither flexible nor reviewable in development of an AIM-mode instrument. For example, the wavelength of operation, NA of the stepper, reticle format and mask feature sizes are specifications defining EUVL lithography technology to which the AIM-mode instrument must conform and is not flexible. However, the values set for these specifications are subject to adjustment pending the final specifications of production exposure tools.

\footnotetext{
"We will use the word "inspection" to refer to an initial measurement procedure performed prior to using this proposed microscope. Inspection rapidly identifies if "light point defects" are present and provides their coordinates for more detailed measurements on other instruments. This microscope will perform the functions referred to as "defect review" or "defect characterization".
} 
Dependent specifications: AIM-mode specification values which result from the fixed specifications of EUVL technology, as defined above. For example the NA of the stepper defines the NA of an AIM-mode instrument, the pupil fill defines the required pupil fills on an AIM tool, and the mask feature size determines the spatial resolution required on the mask. Some of these specifications, for example NA in AIM-mode, are fixed while others, such as the NA in high-resolution mode, are flexible.

Integration specifications: Specifications that are largely dependent on the preferences of the end user. For example a unit must be compatible with a particular mask shop's cleanroom environments, but the specification for cleanliness may vary from company to company or even application to application within a company. While we suggest using data analysis software compatible with existing commercial AIM-mode instruments, this need not necessarily be the case. Often the specifications of this nature are a collaborative negotiation between the use and the instrument maker. 
EUV mask inspection microscope

Top-level specifications

\begin{tabular}{|c|c|c|c|c|}
\hline & & \multicolumn{2}{|c|}{$\begin{array}{l}\text { EUV Actinic Lithography Emulation } \\
\text { (AIM) microscope }\end{array}$} & \multirow[t]{2}{*}{ EUV high-resolution microscope } \\
\hline & 130nm node & 45nm node & 32nm node & \\
\hline \multirow[t]{2}{*}{$\begin{array}{l}\text { Fixed specifications } \\
\text { Stepper technology }\end{array}$} & $\begin{array}{l}\text { 5x DUV optical reduction steppers } \\
\text { Transmissive masks } \\
\text { Telecentric imaging through system }\end{array}$ & \multicolumn{2}{|c|}{$\begin{array}{l}\text { 5x EUV optical reduction MET } \\
0.3 \mathrm{NA} \text { system (0.06NA to mask) } \\
\text { 4x EUV optical reduction steppers } \\
\text { Illumination } 5-7^{\circ} \text { off normal at mask } \\
\text { Imaging telecentric at wafer }\end{array}$} & \\
\hline & \multirow[t]{2}{*}{$\begin{array}{l}0.7 \text { NA projector } \\
(0.14 \text { NA to mask) }\end{array}$} & $\begin{array}{l}0.25 \mathrm{NA} \text { projection } \\
(0.063 \mathrm{NA} \text { to mask) }\end{array}$ & $\begin{array}{l}0.25-0.30 \mathrm{NA} \\
\text { projection } \\
(0 .-63-0.075 \mathrm{NA} \text { to } \\
\text { mask })\end{array}$ & \\
\hline Additional tool capacity & & \multicolumn{2}{|c|}{$\begin{array}{l}4 \mathrm{x} \text { reduction ETS at } 0.1 \mathrm{NA} \\
(0.025 \mathrm{NA} \text { to mask })\end{array}$} & \\
\hline Wavelength & $193 \mathrm{~nm}$ ArF laser & \multicolumn{2}{|c|}{$\begin{array}{l}13.4 \mathrm{~nm} \\
2 \% \text { FWHM bandwidth }\end{array}$} & Same as for EUV AIM-mode system \\
\hline Reticle format & $\begin{array}{l}\text { 6" square } \\
\text { Protective pellicle }\end{array}$ & \multicolumn{2}{|c|}{$\begin{array}{l}\text { 6" square multilayer coated Low Thermal } \\
\text { Expansion Material (LTEM) } \\
\text { per SEMI P37 specification }\end{array}$} & Same as for EUV AIM-mode system \\
\hline Mask feature size & $650 \mathrm{~nm}$ & \multicolumn{2}{|c|}{$\begin{array}{l}180 \mathrm{~nm} \text { (nominal) at } 45 \mathrm{~nm} \text { node } \\
128 \mathrm{~nm} \text { (nominal) at } 32 \mathrm{~nm} \text { node } \\
52 \mathrm{~nm} \text { isolated lines ( } 13 \mathrm{~nm} \text { on wafer) }\end{array}$} & Same as for EUV AIM-mode system \\
\hline \multicolumn{5}{|l|}{ Dependent specifications } \\
\hline $\begin{array}{l}\text { Resolution limit } \\
\qquad \delta=\frac{\lambda}{2 N A}\end{array}$ & $\begin{array}{l}0.1 \mu \mathrm{m} \text { resolution in mask plane claimed } \\
0.2 \mathrm{NA} \text { optics diffraction limited to } 480 \mathrm{~nm}\end{array}$ & $108 \mathrm{~nm}$ at $0.063 \mathrm{NA}$ & $89 \mathrm{~nm}$ at $0.075 \mathrm{NA}$ & $\begin{array}{l}27 \mathrm{~nm} \text { at } 0.25 \mathrm{NA} \\
15 \mathrm{~nm} \text { at } 0.45 \mathrm{NA}\end{array}$ \\
\hline
\end{tabular}




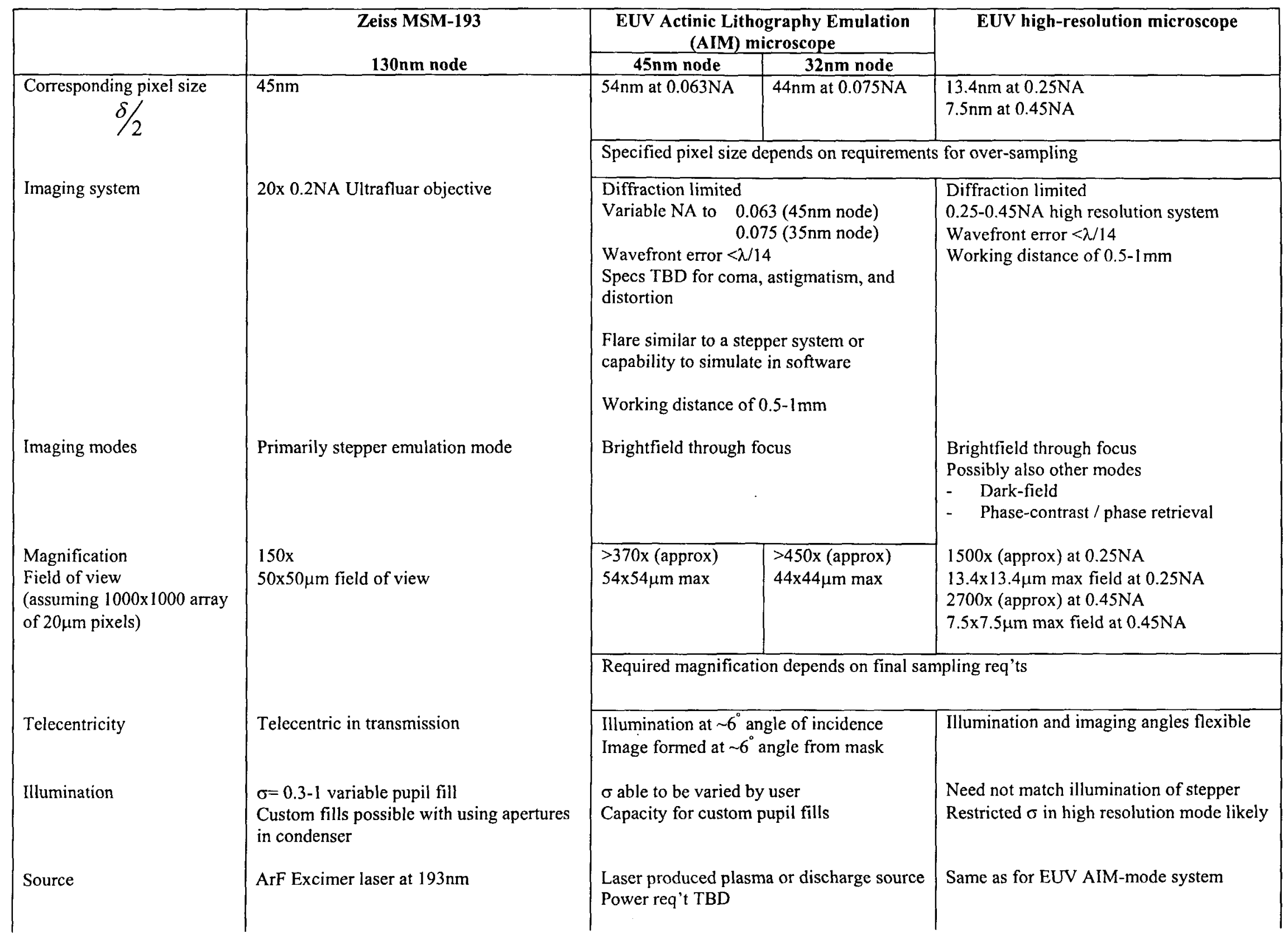




\begin{tabular}{|c|c|c|c|}
\hline & \multirow{2}{*}{$\begin{array}{c}\text { Zeiss MSM-193 } \\
\text { 130nm node } \\
\end{array}$} & $\begin{array}{l}\text { EUV Actinic Lithography Emulation } \\
\text { (AIM) microscope }\end{array}$ & \multirow[t]{2}{*}{ EUV high-resolution microscope } \\
\hline & & \begin{tabular}{|l|l|}
$45 \mathrm{~nm}$ node & $32 \mathrm{~nm}$ node \\
\end{tabular} & \\
\hline Focus control & $25 \mathrm{~mm}$ range in $0.05 \mu \mathrm{m}$ increments & \multirow{2}{*}{$\begin{array}{l}\text { Sub process-window resolution essential } \\
25 \mathrm{~nm} \text { or better suggested } \\
\text { Coarse, low resolution focus control may } \\
\text { be required for loading the mask } \\
\text { Within } 1 \% \text { nominal dose }\end{array}$} & Same as for EUV AIM-mode system \\
\hline Dose control & & & \\
\hline Optical environment & Optics in air & $\begin{array}{l}\text { Optics must be in vacuum } \\
\text { Environmental monitoring system req'd }\end{array}$ & \\
\hline Integration specifications & & & \\
\hline Visual inspection mode & Available & $\begin{array}{l}\text { Visible light imaging mode useful for } \\
\text { preliminary alignment and evaluation }\end{array}$ & Same as for AIM-mode system \\
\hline Stage $\quad(x y)$ & Stage calibrated using fiducials on mask & $\begin{array}{l}0.08 \mu \mathrm{m} \text { resolution, repeatable } \\
\text { Automatic calibration for cross-registration } \\
\text { with other tools required. }\end{array}$ & Same as for AIM-mode system \\
\hline Location and positioning & $\begin{array}{l}\text { Import co-ordinate data from inspection } \\
\text { tools for registration of defects } \\
\text { Capacity for visible-light alignment }\end{array}$ & $\begin{array}{l}\text { Must be able to import data from } \\
\text { inspection tools. }\end{array}$ & Same as for AIM-mode system \\
\hline Analysis software & $\begin{array}{l}\text { AIMS image processing software licensed } \\
\text { from IBM }\end{array}$ & $\begin{array}{l}\text { Software interface should have similar } \\
\text { functionality to the existing AIMS } \\
\text { software from IBM. } \\
\text { Licensing existing software is one option. }\end{array}$ & Same as for AIM-mode system \\
\hline Tool environment & Class 10 cleanroom suggested & $\begin{array}{l}\text { Unit must be compatible with mask shop } \\
\text { environment (Class } 10 \text { cleanroom?) } \\
\text { Load lock for masks makes sense } \\
\text { (technology exists - SEM style) }\end{array}$ & Same as for AIM-mode system \\
\hline Mask handling & $\begin{array}{l}\text { Manual handling } \\
\text { Masks loaded by hand directly onto stage }\end{array}$ & $\begin{array}{l}\text { Vacuum environment will require either } \\
\text { - some form of robotic load-lock, or } \\
\text { - long pumpdown times between runs } \\
\text { Must not add any defects to the mask } \\
\text { SMIF pod interface, no agreement on type }\end{array}$ & Same as for AIM-mode system \\
\hline Throughput & $\begin{array}{l}\text { Individual images limited by CCD speed } \\
\text { Overall throughput limited by stages and }\end{array}$ & $\begin{array}{l}\text { Approx } 5 \text { mins to load mask via load-lock } \\
\text { Imaging limited by data capture rate }\end{array}$ & \\
\hline
\end{tabular}




\begin{tabular}{|c|c|c|c|c|}
\hline & & $\begin{array}{r}\text { EUV Actinic } \\
\text { (AII }\end{array}$ & $\begin{array}{l}\text { phy Emulation } \\
\text { scope }\end{array}$ & EUV high-resolution microscope \\
\hline & $130 \mathrm{~nm}$ node & $45 \mathrm{~nm}$ node & 32nm node & \\
\hline & loading time & & & \\
\hline Vibration specs & $<2 \mu \mathrm{m}$ amplitude in range $0.1-100 \mathrm{~Hz}$ & Will depend on & echanics & \\
\hline Ergonomic format & $\begin{array}{l}\text { Bench-top computer-controlled } \\
\text { microscope }\end{array}$ & $\begin{array}{l}\text { Benchtop footpr } \\
\text { may resemble S }\end{array}$ & ompact source & \\
\hline System control & $\begin{array}{l}\text { Can use eyepieces for visible inspection } \\
\text { Integrated controller }\end{array}$ & $\begin{array}{l}\text { PC interface for } \\
\text { Subsystems tran } \\
\text { integrated contr } \\
\text { functions }\end{array}$ & $\begin{array}{l}\text { ystem control } \\
\text { user with single } \\
\text { Il non-imaging }\end{array}$ & \\
\hline Physical size & $\begin{array}{l}1.8 \times 1 \times 1.8 \mathrm{~m} \text { footprint }(\mathrm{LxWxH}) \\
2 \times 1.3 \times 1.8 \mathrm{~m} \text { floorspace } \\
200 \mathrm{~kg}, 500 \mathrm{VA} \text { power consumption }\end{array}$ & $\begin{array}{l}\text { To be determine } \\
\text { Less than } 2 \times 2 \times 2\end{array}$ & $\begin{array}{l}\text { dependent) } \\
\text { including source }\end{array}$ & \\
\hline
\end{tabular}




\section{Notes on the specifications}

\section{$2.1 \quad$ Target node}

Entry of EUV technology is currently anticipated at the $45 \mathrm{~nm}$ node, however the technology is scalable to the $32 \mathrm{~nm}$ node and beyond. It therefore makes sense to similarly target any AIM tool at the $45 \mathrm{~nm}$ node with technology scalable to $32 \mathrm{~nm}$ and beyond if possible. It might be desired for an instrument to immediately target the $32 \mathrm{~nm}$ node, since Sematech will install the 0.3NA MET in 2004, and be able to image defects consistent with the $32 \mathrm{~nm}$ node. It might also be desireable for the AIM mode instrument to operate with an NA compatible with the ETS, which would be $0.1 / 4=0.025$. For MET, $0.3 \mathrm{NA} / 5=0.60$.

\subsection{Spatial resolution}

The incoherent resolution limit of an optical system is at $k_{1}=0.5$, thus the smallest feature size we expect to resolve at a given NA is at $\delta=\lambda / 2 N A$. To adequately sample this image we must use a detector with sufficient resolution to sample at or above the Nyquist frequency, pixel spacing, which refers to the center point of the photosensitive element, must be $\Delta x=\delta / 2$ or smaller. This assumes perfect idealized pixels, but the CCD pixels themselves also contribute to the total transfer function of the system. Thus, in practice, it is necessary to oversample the image by some factor so as to ensure accurate image measurement. As the design process proceeds, the required level of oversampling should be reconsidered and pixel spacing will likely take a value between $\delta / 4$ and $\delta / 2$. Assuming for the moment detection at the Nyquist frequency of $\Delta x=\delta / 2$ or smaller the maximum spatial resolution and corresponding pixel sizes are thus as follows:

\begin{tabular}{|c|c|c|c|}
\hline Mode & NA & Resolution limit & Pixel size at mask \\
& & $\delta=\frac{\lambda}{2 N A}$ & $\Delta x=\frac{\delta}{2}=\frac{\lambda}{4 N A}$ \\
\hline Actinic stepper simulation & $0.25 \mathrm{NA}$ at $4 \mathrm{x}=0.0625 \mathrm{NA}$ & $108 \mathrm{~nm}$ & $54 \mathrm{~nm}$ \\
Mode & $0.3 \mathrm{NA}$ at $4 \mathrm{x}=0.075 \mathrm{NA}$ & $89 \mathrm{~nm}$ & $44 \mathrm{~nm}$ \\
\hline High resolution mode & $0.25 \mathrm{NA}$ & $27 \mathrm{~nm}$ & $13.4 \mathrm{~nm}$ \\
& $0.45 \mathrm{NA}$ & $15 \mathrm{~nm}$ & $7.5 \mathrm{~nm}$ \\
\hline
\end{tabular}

To emulate a $0.25 \mathrm{NA}$ stepper with a reduction factor of $4 \mathrm{x}$ the mask-side pupil is at $0.0625 \mathrm{NA}$, thus the spatial resolution of the stepper on the mask is $\delta=108 \mathrm{~nm} .54 \mathrm{~nm}$ pixels are therefore required to adequately sample the image.

Operating at $0.45 \mathrm{NA}$ in high resolution mode much smaller pixels are required: at $0.45 \mathrm{NA} \delta=15 \mathrm{~nm}$ thus necessitating $7.5 \mathrm{~nm}$ pixels at the mask to fully take advantage of the higher resolution.

It is important to consider that oversampling the image may be advantageous in minimizing OTF roll-off. Therefore the desired pixel sizes may up to $2 x$ smaller.

\subsection{Detector specifications}

Detector specifications are system dependent and are not considered in this section. The detector will vary depending on the optical system configuration and could take the format of a $C C D$, photocathode, image plate, or other system. For the sake of convenience we have assumed a $1000 \times 1000$ array of $20 \mu \mathrm{m}$ pixels as a baseline reference in this document.

\section{$2.4 \quad$ Optical system}

Feedback from industry is that the optical resolution should not be compromised. Aim for a higher magnification and smaller pixel size than available on current tools (relative to mask feature size) if possible.

\subsubsection{Numerical aperture (stepper emulation mode)}

The imaging system must have an NA equal to or greater than the input NA of the stepper so as to be able to accurately simulate the stepper imaging performance. Systems with smaller NA than the objective can be emulated by inserting apertures into the system thus it is prudent to err on the side of higher NA if possible. To be compatible with a $0.3 \mathrm{NA} 4 \mathrm{x}$ reduction stepper system for use at the $32 \mathrm{~nm}$ node therefore requires a mask-side NA of 0.075 .

\begin{tabular}{|c|c|}
\hline Stepper NA & Mask-side NA \\
\hline 0.25 NA stepper at 4x reduction & 0.0625 \\
0.3 NA stepper at 4x reduction & 0.075
\end{tabular}




\begin{tabular}{|c|c|}
$0.3 N A$ MET at $5 x$ reduction & 0.06 \\
0.1 NA ETS tool at $4 x$ reduction & 0.025 \\
\hline
\end{tabular}

\subsubsection{Numerical aperture (high resolution mode)}

For higher resolution imaging it is necessary to go to a higher NA optical system. As the system does not have to emulate the NA of a stepper there is some choice in the selection of NA, subject to the limitations of particular system configurations.

One potential use of an AIM system is for the classification of phase and amplitude defects. For this application calculations indicate that the numerical aperture required to distinguish between phase and amplitude defects of height is of the form $a<w N A / 1.72$ where $\mathrm{a}$ is the height of the bump and $w$ its Gaussian radius on the mask. Not all defects can be repaired, and preliminary calculations indicate that that an NA of at least 0.2 should be adequate to cover repairable defects.

\subsubsection{Telecentricity}

Whilst DUV systems are telecentric, in an EUV system the reflective mask is illuminated at $\sim 6$ degrees and the reflected light is collected at the same angle but on the opposite side of the normal. This places some limitation on the available ranges of mask side $\mathrm{NA}$ if the imaging optics are not to occlude the illumination beam. For the incoming beam not to occlude the outgoing beam, we need $\theta_{1}+\theta_{2}<12$ degrees, where $\sin \left(\theta_{1}\right)=\sigma^{*} \mathrm{NA}$ and $\sin \left(\theta_{2}\right)=\mathrm{NA}$. For $\sigma=1$, this means the maximum $N A$ is equal to $\sin (6$ degrees $)=0.104$.

Illumination at 6 degrees also causes a lateral image shift as the stage is moved through focus. This can be compensated for by either translating the stage as focus is changed, or by making the imaging system telecentric at the detector and defocusing the detector rather than the mask. To avoid image processing and overlay problems the latter approach would be preferable, but is dependent on system design.

\subsubsection{Working distance}

The current AIM tool has a working distance of $7.4 \mathrm{~mm}$ to accommodate masks with protective pellicles. There is no suggestion that EUV masks will be protected by pellicles of this thickness so there is no need to maintain this requirement for an EUV system. In the absence of a pellicle the minimum working distance is set by practical considerations such as mask mounting and positioning error. To provide some margin of error in positioning the stage and objective to minimize the danger of damaging the mask. The working distance available on current metallurgical objectives for visible light microscopes is of the order of 0.5 to $1 \mathrm{~mm}$, and this would appear to be a reasonable starting figure for an EUV tool.

\subsubsection{Magnification}

The required magnification will depend on the type of detector used and is therefore not a fixed value. Potential detectors include, but are not limited to, a CCD, image plate, photocathode or scintillator, all of which have different effective pixel sizes and therefore different required magnifications.

Working for the moment on assumption that the final detector will be a CCD with $20 \mu \mathrm{m}$ pixels the required magnification can be computed from the ratio of the desired pixel size in the mask plane to the size of the CCD pixels in the image plane. For a detector with a $20 \mu \mathrm{m}$ pixel size this gives a total system magnification of $370 \mathrm{x}$ if we operate only in AIM mode, but a magnification of $2700 \mathrm{x}$ if we also include a $0.45 \mathrm{NA}$ high-resolution mode.

\subsubsection{Field of view}

The useful field of view is determined by either distortion and aberrations across the field in the optical system or by the number of pixels in the detector. Optical effects depend on a combination of lens design and the final system configuration selected, whilst in a scanning system the number of pixels is effectively unlimited thus there is no effective upper bound to the field of view other than the time taken to acquire the image.

To provide some estimate of the field size a discussion is presented based on the number of pixels in the detector. Typical CCD array sizes are of the order of 1000x1000 pixels, which gives maximum a field of view given by the pixel resolution on the mask times the number of pixels. If we operate with a system that is only capable of operating in AIM mode with $54 \mathrm{~nm}$ pixels we will have a field of view of $54 \mu \mathrm{m}$, whilst if we construct a high-resolution $0.45 \mathrm{NA}$ system and stop it down for operation in AIM mode we will have a field of view of only $7.5 \mu \mathrm{m}$ even in AIM mode. Note that this is the field of view for a single CCD exposure - multiple exposures can be stitched together in software to create a virtual field much larger than this size.

\subsection{Illumination}

\subsection{AIM mode}

To properly emulate the function of a stepper it is essential to have the capacity to emulate the pupil fill of a production system. Pupil fills may vary amongst manufacturers and with machine generation, thus it is essential not to tie the illumination system to one particular optical system. Some capacity to produce custom fills is essential, and could be achieved either by the use of apertures in the illuminator or by a scanning mirror that paints out a pupil fill during the course of an exposure. 


\subsubsection{High resolution mode}

For highest spatial resolution it is best to use a large pupil fill. However, the EUV the reflectivity of a multilayer is strongly dependent on the angle of incidence thus full pupil fill may not be practical when operating the microscope in high resolution 'microscope' mode. Furthermore because an EUV system operates in reflection rather than transmission it may not be possible to obtain full pupil fill in high-resolution mode because the obscuration caused by the optical elements themselves may provide some limitation on the range of available pupil fills.

Some of these constraints will be imposed by the particular imaging systems that restrict the range of available apertures. The proper place to consider these is in relation to the individual imaging systems, so discussion of available pupil fills for high-resolution mode is deferred to the system-level discussion. Some consideration also must be given to the use of either critical or Köhler illumination modes.

\subsection{Stage travel $(x-y)$}

Keeping the ratio of mask feature size to stage resolution consistent with that on current AIM tools gives a required stage resolution in the EUV of $0.08 \mu \mathrm{m}$. This is the same as the optical spatial resolution of is $0.08 \mu \mathrm{m}$ obtained when emulating a $4 \times 0.3 \mathrm{NA}$ stepper $(0.075 \mathrm{NA}$ to the mask). In high resolution mode the field size is of the order of $7.5 \times 7.5 \mu \mathrm{m}$, and a stage of this accuracy should enable positioning of the mask to sufficient accuracy that the desired feature will be well placed within the field of view to within 10 pixels.

A repeatable positioning resolution of $80 \mathrm{~nm}$ is only slightly more than $1 / 6$ of a wavelength at $500 \mathrm{~nm}$ and so should be well within the resolution of interferometric optical encoders. The stage co-ordinates must also be able to be calibrated with regard to fiducials on the mask for the purposes of cross-registration with other tools, and must be done automatically and transparently to the user in software. A system similar to that in use on current AIMS tools would suffice.

\subsection{Focus control}

It is essential that the focus control have better resolution than the process window of a stepper. The mask flatness spec is $50 \mathrm{~nm}$, and to sample this adequately it would be necessary to have $25 \mathrm{~nm}$ focus resolution. Capacity to resolve a factor of $2-5$ better than the mask flatness spec may be desirable for some high-precision analysis modes.

Note that a leverage factor of the magnification squared can be obtained by defocusing the detector rather than the mask. There could be significant advantage to this approach: not only does it provide a ready method for obtaining fine focus control, but it also eliminates image shifts as the focus is changed if the imaging system is made telecentric at the detector. It is also worth pointing out that focus control can be separate from the mechanics of moving the mask in the Z-direction. Piezoelectric actuators are ideally suited to the fine focus resolution required for probing the process window, whilst a coarser system would be adequate for moving the mask into the focus range of the microscope.

\subsection{Throughput}

The desired throughput is to a certain extent user-defined. On current tools a good operator can cycle a mask (set up, align, image, remove) about one mask per half an hour, with 5 minutes per exposure (find, focus, capture, etc.). Similar or better turnaround time should be targeted for on an EUV inspection tool, although this spec will have to be refined in consultation with potential users given the application in mind.

There are two fundamental limiting factors on throughput: data capture rate and loading rate. The need for a vacuum environment for EUV will make the system slower to load than current systems that operate in air. As a guide, on current SEMs it takes 5 minutes to load a 6 " wafer down to a vacuum of approx $10^{-11}$ Torr operating pressure. EUV optics don't require such a high vacuum so this would be a reasonable upper bound on the desired loading rate. Total mask throughput would then be governed by how fast a mask can be loaded and focussed, and to a certain extent by stage speed (for example the need for calibration and accurate registration). A 5 minute vacuum load is not inconsistent with current thoughput rates and could be made a negligible limiting factor with some automation of the system (for example by imaging one mask while pumping down the next).

The data capture rate is limited by either the CCD imaging speed (data download rate) or source power (getting enough photons onto the $\mathrm{CCD}$ ). Data processing can be solved with faster computers, whilst good system integration should mean that little time is spent configuring the machine. Ideally, an EUV tool should be data rate rather than source limited; a high-resolution scientific grade CCD takes a few seconds to download an entire image, so individual frame exposure times of less than a second should be aimed for.

\subsection{Environment}

Current AIM tools suggest a class- 10 cleanroom environment and are compatible with the cleanroom environment of a mask shop. Similarly an EUV tool will also have to be compatible with mask shop cleanrooms, although the use of SMIF loading pods and robotic handling may mean that only the loading area and inside of the tool need be within the cleanroom. The cleanliness requirement is an issue to be determined between the supplier and customer. 
There is, however, some difference in the optics and the requirement to use a vacuum for EUV. 193nm optics can work in an air environment whilst EUV optics must be housed in vacuum because the absorption length of $13.5 \mathrm{~nm}$ light in air is less than the optical path in the imaging system. This means that specifications are required for cleanliness of the vacuum environment. This should be as clean as the mask area of a production stepper so as to minimize the number of defects added. 